\title{
Numerical Simulation of Transient Moisture Transfer into an Electronic Enclosure
}

\author{
Shojaee Nasirabadi, Parizad; Jabbaribehnam, Mirmasoud; Hattel, Jesper Henri
}

Published in:

A I P Conference Proceedings Series

Link to article, DOI:

$10.1063 / 1.4951794$

Publication date:

2016

Document Version

Publisher's PDF, also known as Version of record

Link back to DTU Orbit

Citation (APA):

Shojaee Nasirabadi, P., Jabbaribehnam, M., \& Hattel, J. H. (2016). Numerical Simulation of Transient Moisture Transfer into an Electronic Enclosure. A I P Conference Proceedings Series, 1738, [030038].

https://doi.org/10.1063/1.4951794

\section{General rights}

Copyright and moral rights for the publications made accessible in the public portal are retained by the authors and/or other copyright owners and it is a condition of accessing publications that users recognise and abide by the legal requirements associated with these rights.

- Users may download and print one copy of any publication from the public portal for the purpose of private study or research

- You may not further distribute the material or use it for any profit-making activity or commercial gain

- You may freely distribute the URL identifying the publication in the public portal

If you believe that this document breaches copyright please contact us providing details, and we will remove access to the work immediately and investigate your claim 


\title{
Numerical Simulation of Transient Moisture Transfer into an Electronic Enclosure
}

\author{
P. Shojaee Nasirabadi, M. Jabbari and J.H. Hattel \\ Process Modelling Group, Department of Mechanical Engineering, Technical University of Denmark, Nils \\ Koppels Allé, 2800 Kgs. Lyngby, Denmark.
}

\begin{abstract}
Electronic systems are sometimes exposed to harsh environmental conditions of temperature and humidity. Moisture transfer into electronic enclosures and condensation can cause several problems such as corrosion and alteration in thermal stresses. It is therefore essential to study the local climate inside the enclosures to be able to protect the electronic systems. In this work, moisture transfer into a typical electronic enclosure is numerically studied using CFD. In order to reduce the CPU-time and make a way for subsequent factorial design analysis, a simplifying modification is applied in which the real $3 \mathrm{D}$ geometry is approximated by a $2 \mathrm{D}$ axial symmetry one. The results for $2 \mathrm{D}$ and $3 \mathrm{D}$ models were compared in order to calibrate the 2D representation. Furthermore, simulation results were compared with experimental data and good agreement was found.
\end{abstract}

Keywords: moisture, diffusion, $\mathrm{CFD}$, enclosure.

PACS: 80A20

\section{INTRODUCTION}

Electronic enclosures serve several packaging functions, such as cooling, touch protection, input-output, IP, and appearance. Unless the enclosure is perfectly sealed and made in truly hermetic materials, moisture may enter it [1]. Moisture can cause corrosion in electronic systems; especially in the presence of ionic contaminants. It can also accelerate electrochemical metal migration mechanisms [2]. In fact, high relative humidity may lead to condensation of water on the metal surfaces. The concentration of molecules of water vapor rises with increasing relative humidity. This molecular thickness of the layers of water may eventually permit ionic conduction that accelerates the rate of corrosion [3]. These degradation mechanisms can lead to changes in electrical resistance and eventually short circuits [2]. Hence, in order to protect electronic devices from the effects of water vapor, it is essential that the relative humidity inside the enclosure does not reach a level that threatens the electronic function within the required lifetime [4].

Modelling tools describing the moisture behavior are very useful to predict and evaluate moisture related problems and in this content computational fluid dynamics (CFD) has been used as a powerful tool for predicting detailed indoor environmental conditions [5] . Using CFD, air and moisture transport into an enclosure can be simulated with perfect control of all boundary conditions. Furthermore, CFD modelling is an alternative to often expensive and tedious experiments [6]. A full blown CFD model does not require transfer coefficients to model the interaction between fluid and solid interface since this is inherently part of the solution itself. Moreover, CFD allows the analysis of complex geometries and provides detailed information on temperature and humidity distributions. One major drawback of CFD though, is the high computational cost [7].

The purpose of this study is to investigate the moisture transfer into a typical electronic enclosure through an opening. To achieve this, transient moisture transfer into a typical electronic enclosure with a bottom hole is studied using CFD. A modified 2D geometry is studied to check whether it is possible to simplify the 3D geometry and reduce calculation time and the results are compared with the real 3D geometry. Furthermore, moisture transfer into a typical electronic enclosure located in a controlled chamber is modelled and the results are validated with experimental data. Thus, this work has two parts as follows: (i) comparison between 3D and modified 2D geometry and (ii) validation of the modeling with experimental data. 


\section{MODEL FORMULATION}

A scheme of the investigated geometries for the 2D and 3D studies is shown in Figure 1. Dimensions are shown in Table1. Mass conservation equations are solved for both the surrounding (inside the chamber) and inside the enclosure. Regarding the fact there is no air flow inside the enclosure, moisture is transferred only trough diffusion there. On the other hand for the surrounding (inside the climatic chamber), both convection and diffusion are responsible for the moisture transfer because of the air flow. Velocity distribution inside the climatic chamber was provided by solving momentum conservation equations. All simulations are performed with the commercial code COMSOL Multiphysics ${ }^{T M}$. The backward differentiation formula (BDF) method was used for time stepping. The BDF method is an implicit method that uses known solution data determined at several previous time points as well as the unknown solution at the current point. The order of the error term can be easily adjusted by choosing a different number of previous data points. In this work, the minimum and the maximum BDF order is 1 and 2, respectively.
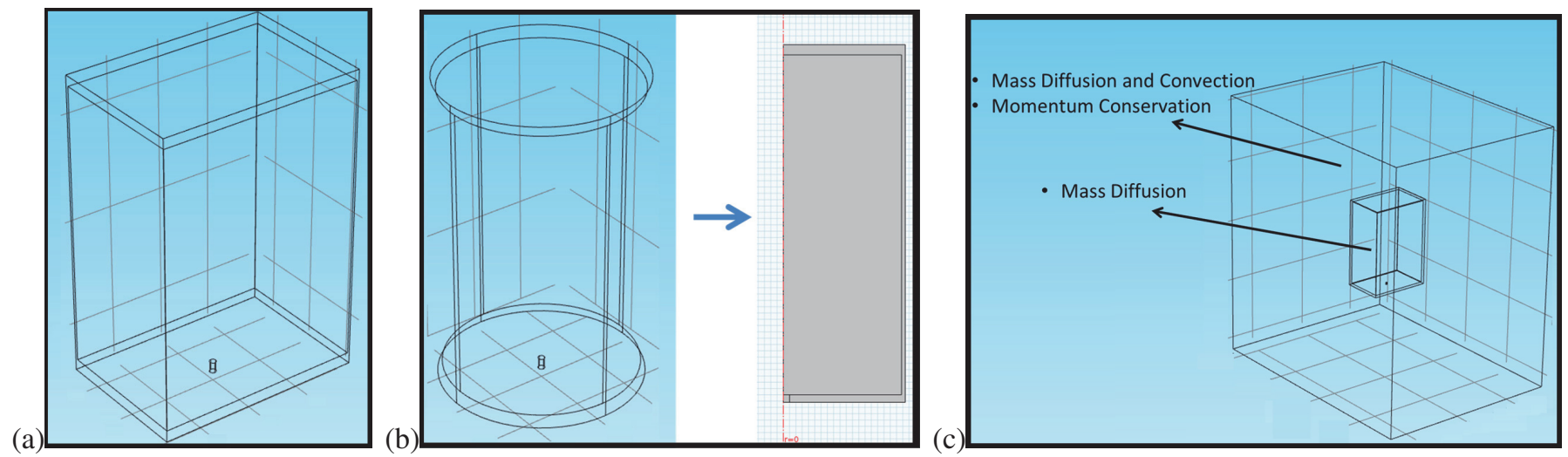

FIGURE 1. (a) schematic of the real 3D geometry (b) schematic of the modified geometry and its $2 \mathrm{D}$ axial symmetry form (b) schematic of the 3D geometry of the enclosure located in the controlled climatic chamber and the solved physics.

TABLE 1. Dimensions of the investigated geometries

\begin{tabular}{lcc}
\hline Enclosure & Inner dimensions $(\mathrm{mm})(\mathrm{W} \times \mathrm{D} \times \mathrm{L})$ & $188 \times 128 \times 276$ \\
& Outer dimensions $(\mathrm{mm})(\mathrm{W} \times \mathrm{D} \times \mathrm{L})$ & $190 \times 130 \times 280$ \\
Chamber & Inner dimensions $(\mathrm{mm})(\mathrm{W} \times \mathrm{D} \times \mathrm{L})$ & $600 \times 800 \times 850$ \\
Hole & Diameter $(\mathrm{mm})$ & 2 \\
& Height $(\mathrm{mm})$ & 2 \\
\hline
\end{tabular}

Mass conservation equations are solved for both the surrounding (inside the chamber) and inside the enclosure. Regarding the fact there is no air flow inside the enclosure, moisture is transferred only trough diffusion. On the other hand for the surrounding (inside the climatic chamber), both convection and diffusion are responsible for the moisture transfer because of the air flow. Velocity distribution inside the climatic chamber was provided by solving momentum conservation equations (see Figure 2).

\section{MASS BALANCE EQUATION}

Equation1 describes chemical species transport through diffusion and convection and implements the mass balance equation:

$$
\frac{\partial c}{\partial t}+\mathbf{u} \cdot \nabla c=\nabla \cdot(D \nabla c)
$$

Where

- $c$ is the concentration of the species (mole $/ \mathrm{m}^{3}$ )

- $D$ denotes the diffusion coefficient $\left(\mathrm{m}^{2} / \mathrm{s}\right)$

- $\mathbf{u}$ is the velocity vector $(\mathrm{m} / \mathrm{s})$ 
the first term on the left-hand side corresponds to the accumulation of the species. The second term accounts for the convective transport due to a velocity field $u$. On the right-hand side of the mass balance equation, the term describes the diffusion transport. This equation is fully solved for the climatic chamber where both mass diffusion and convection happens. For inside the enclosure, since there is no fluid flow, equation (1) reduces to the following equation (Fick's second law):

$$
\frac{\partial c}{\partial t}=\nabla \cdot(D \nabla c)
$$

\section{Momentum Balance Equation}

Momentum Balance Equation is solved for part (ii) where a chamber provides a certain magnitude of relative humidity $(\mathrm{RH})$ by flowing humid air inside. In this study all the simulations were done under the isothermal $\left(25^{\circ} \mathrm{C}\right)$ assumption. It should be noticed that $\rho$ and $\mu$ for humid air are function of humidity; however, at $25^{\circ} \mathrm{C}$ the changes are negligible and do not violate the assumption of constant viscosity and density [8]. It is worth to mention that $\mathrm{D}$ is a weak function of RH; thus, it was also considered to be constant. For constant $\rho$, the momentum equation is:

$$
\rho \frac{\partial \mathbf{u}}{\partial t}+\rho(\mathbf{u} \cdot \nabla) \mathbf{u}=\nabla \cdot\left[-p \mathbf{I}+\mu\left(\nabla \mathbf{u}+\left(\nabla \mathbf{u}^{\top}\right)\right)+\mathbf{F}\right]
$$

Where

- $\rho$ is the density

- $p$ is pressure

- $\mu$ is the viscosity

- $\mathbf{F}$ is the volume force vector.

To solve the momentum balance equation inside the controlled chamber, the velocity was set to $0.1 \mathrm{~m} / \mathrm{s}$ at the top face of the chamber and the bottom face of the chamber was considered an outlet with normal flow. Pressure drop and gravity effects were neglected. The momentum transfer is fast for the flowing humid air and the steady state condition is reached in a short period of time; thus, the first term on the left side of Equation 3 can be neglected and velocity distribution can be considered constant during the time. Furthermore, regarding the constant $\rho$ assumption, the continuity equation reduces to:

$$
\rho \nabla \mathbf{u}=0
$$

\section{RESULTS AND DISCUSSION}

\section{Simplifying the 3D Geometry to 2D Geometry}

Replacing the cubic enclosure with 2D axial symmetry geometry of the same volume and the same height, a modified 2D geometry is proposed (see Figure 1(b)). A constant relative humidity of $98 \%$ was applied as boundary condition at the opening for both the 2D and 3D geometries. Figure 2 displays the results.

\section{Comparison of the Numerical Simulation with Experimental Data}

An enclosure with a bottom hole located in a controlled chamber is numerically simulated and the results are compared with the experiment in Figure 3. The experimental data are taken from a study done by Conseil et al [9]. RH inside the chamber is kept at $98 \%$ at a constant temperature of $25^{\circ} \mathrm{C}$. The initial relative humidity inside the enclosure is $28 \%$. 


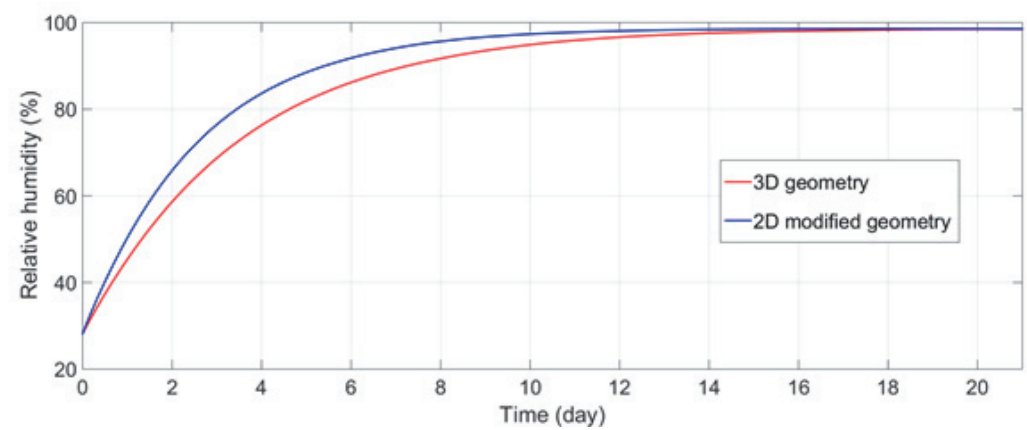

FIGURE 2. Numerical simulation of moisture transfer into an enclosure in case of a 3D and modified 2D geometry

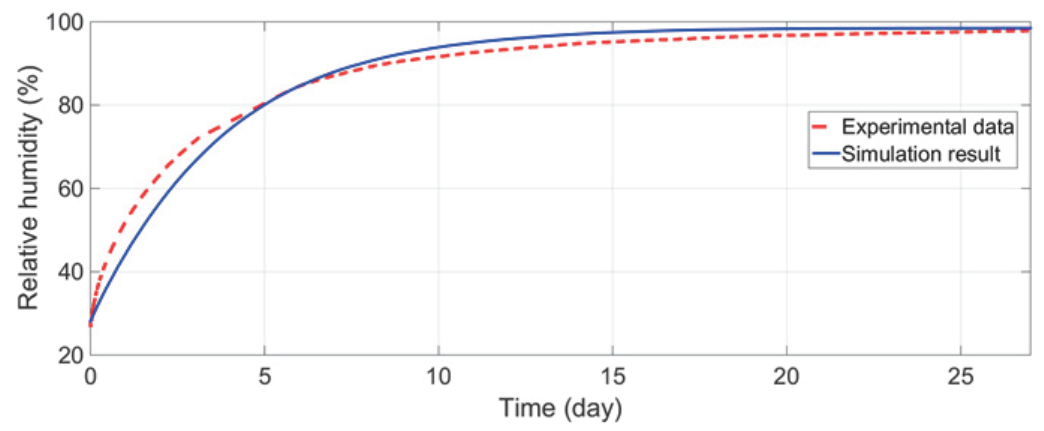

FIGURE 3. Comparison of the numerical simulation with experimental data

\section{CONCLUSIONS}

Transient moisture transfer into a typical electronic enclosure was numerically studied using CFD. Fick's second law could successfully predict the local climate of the enclosure exposed to an environment with a high relative humidity (98\%). Simulation results also revealed that moisture transfer into an enclosure with a circular base takes less time compared with a rectangular base one of the same volume and height.

In future work, the 2D model will be used as the modelling basis for a 2-level factorial design where influential parameters on the moisture transfer inside the enclosure will be analysed.

\section{REFERENCES}

1. J. B. Jacobsen, J. P. Krog, A. H. Holm, L. Rimestad, and A. Riis, IEEE Ind. Electron. Mag. 8 (2014).

2. O. Leslie, and A. Oasgupta, "Quantifying Moisture Diffusion into Three-Dimensional Axisymmetric Sealants," in EuroSimE 14th international Conference on Thermal, Mechanical and Multi-Physics Simulation and Experiments in Microelectronics and Microsystems, 2013.

3. R. Ciprian, and B. Lehman, "Quantifying Moisture Diffusion into Three-Dimensional Axisymmetric Sealants," in IEEE Energy Conversion Congress and Exposition(ECCE), 2009.

4. N. Dahan, A. Vanhoestenberghe, and N. Donaldson, IEEE Trans. Compon. Packag. Manuf. Technol. 2 (2012).

5. F. Song, B. Zhao, X. Yang, Y. Jiang, V. Gopal, G. Dobbs, and M. Sahm, Build. Environ. 43 (2008).

6. M. Delele, A. Schenk, E. Tijskens, H. Ramon, B. NicolaÃŕ, and P. Verboven, J. FOOD ENG. 91 (2009).

7. M. V. Belleghem, H.Steeman, M. Steeman, A. Janssens, and M. D. Paepe, Build. Environ. 45 (2010).

8. P. Tsilingiris, ENERG. CONVERS. MANAGE. 49 (2008).

9. H. Conseil, M. S. Jellesen, and R. Ambat, "Experimental Study of Water Absorption of Electronic Components and Internal Local Temperature and Humidity into Electronic Enclosure," in 2014 IEEE 16th Electronics Packaging Technology Conference (EPTC), 2014. 